\title{
Fast-Clamped Short-Circuit Protection of IGBT's
}

\author{
Vinod John, Student Member, IEEE, Bum-Seok Suh, and Thomas A. Lipo, Fellow, IEEE
}

\begin{abstract}
Identification of fault current during the operation of a power semiconductor switch and activation of suitable remedial actions are important for reliable operation of power converters. A short circuit is a basic and severe fault situation in a circuit structure, such as voltage-source converters. This paper presents a new active protection circuit for fast and precise clamping and safe shutdown of fault currents of the insulated gate bipolar transistors (IGBT's). This circuit allows operation of the IGBT's with a higher on-state gate voltage, which can thereby reduce the conduction loss in the device without compromising the shortcircuit protection characteristics. The operation of the circuit is studied under various conditions, considering variation of temperature, rising rate of fault current, gate voltage value, and protection circuit parameters. An evaluation of the operation of the circuit is made using IGBT's from different manufacturers to confirm the effectiveness of the protection circuit.
\end{abstract}

Index Terms - Fault current, fault under load, hard-switched fault, insulated gate bipolar transistors, protection, short circuit.

\section{INTRODUCTION}

$\mathbf{S}$ HORT CIRCUIT and overcurrent are severe fault conditions that can result in failure of the insulated gate bipolar transistor (IGBT) if appropriate remedial action is not taken within a short time of the order of a few microseconds. It is shown in [1] that the internal failure mechanism in IGBT's during short circuit is different from the case of hardswitching inductive turn-off failure. Short circuit results in local heating closer to the gate oxide in the IGBT and can severely degrade the device. The excessive power dissipation in the IGBT during the fault leads to chip heating, which eventually destroys the device. Several methods for protection of the IGBT are available that are used in intelligent power modules and advanced gate driver chips [2]-[4]. However, there are no benchmarks for the performance of these circuits.

Various approaches to protect IGBT's have been proposed and studied in [5]-[12]. Different topologies for fault-currentlimiting circuits (FCLC's) have been investigated in [5] and [6]. The technique used in [5], which utilizes a capacitor to reduce the gate voltage after the fault, has the limitation that the device current may shut off and be turned back on again,

Paper IPCSD 98-73, presented at the 1998 IEEE Applied Power Electronics Conference and Exposition, Anaheim, CA, February 15-19, and approved for publication in the IEEE TRANSACTIONS ON INDUSTRY APPLICATIONS by the Industrial Power Converter Committee of the IEEE Industry Applications Society. Manuscript released for publication October 27, 1998.

V. John and T. A. Lipo are with the Department of Electrical and Computer Engineering, University of Wisconsin, Madison, WI 53706 USA.

B.-S. Suh was with the Department of Electrical and Computer Engineering, University of Wisconsin, Madison, WI 53706 USA. He is now with the IGBT/MOSFET Group, Discrete Team, Samsung Electronics, Puchon-City, Kyonggi Province, 420-711 Korea.

Publisher Item Identifier S 0093-9994(99)02239-2. depending on the initial condition of the capacitor and its value. Also, a large value of capacitance is necessary to prevent the capacitor voltage from drifting back to the normal on-state gate voltage. Multiple stages of clamping are proposed in [5] to increase the endurance time and reduce the turn-off current level. A pure zener-based clamp has the drawback that the clamping gate voltage can be much larger under the transient conditions of the fault. Reference [6] discusses a topology where the zener and capacitive method is used to limit fault currents. This circuit is effective in eventually clamping the fault current level, but does not limit the large peak current that flows immediately after the fault due to delay in its operation. References [7]-[12] discuss methods to softly turn off the IGBT after the fault and to reduce the overvoltage due to the turn-off $d i / d t$. The purpose is to control the overvoltage caused by the parasitic inductance of the power circuit while turning off large currents.

This paper focuses on the following study issues for active protection of fault currents for IGBT modules.

- Use of a large on-state gate voltage to reduce conduction losses makes the fault situation more problematic and dangerous, because it leads to very high fault current. This results in large instantaneous power dissipation [13] and the possibility of latching in the device. Therefore, there is a tradeoff between the short-circuit current magnitude and the conduction loss.

- Precise detection of fault current levels is a challenging issue if current sensors are not used in series with the IGBT's. In particular, in case of large fault inductance (soft fault) it is difficult to precisely recognize the overcurrent condition using the de-saturation technique, which is a common method used to identify a fault situation. This is due to the reduced voltage drop in the IGBT under low $d i / d t$ conditions, as well as the slow dynamics in the electronic components in the detection circuit.

- Fast detection and reliable handling of fault currents are important study issues. The initial value of short current is the highest due to the increased gate voltage caused by the Miller capacitance. It is not easy to reduce the initial peak current, because activation of protection circuit should be prevented during the turn-on transient conditions of the IGBT, and during noise phenomena caused by the IGBTs' switching in the power converter;

- At shutdown, the falling rate of the current should be controlled to reduce the overvoltage stress. The overvoltage level across the device can become much larger than the rated voltage, if the large collector current is turned off without any treatment. While using an FCLC, soft turn-off 
requires one to take into account possible changes in the operating modes of the protection circuit.

For the study mentioned above, experimental investigation on the fault situation is performed in detail for the cases of variation of temperature, rising rate of fault current, positive gate voltage level, and circuit parameters. A new active protection method is proposed, which can limit fault currents to a reasonable level while suppressing the initial peak current value and safely shut down the IGBT. Test results are given by using IGBT's from different manufacturers to study operation of the protection circuit under varying device parameters.

\section{OPERATION CHARACTERISTICS OF THE Proposed ACTIVE Protection Circuit}

Fast detection of the occurrence of the fault, limiting of the initial peak current, clamping of the overcurrent, and safe shutdown are essential features of the protection circuit. The types of short-circuit faults that can occur in an IGBT can be classified as hard-switched fault (HSF) and fault under load (FUL) [14]. HSF occurs when the IGBT tries to turn on into a short circuit. FUL is the case where the short circuit occurs when the IGBT is in the on state conducting normal load current. Fig. 1 shows the schematic of the proposed circuit, which is composed of the basic drive circuit, the additional protective control circuit, and the three feedback lines, which are collector voltage detection, collector desaturation voltage, and power emitter voltage. Functions and operational characteristics of the circuit are explained.

\section{A. Detection}

The detection of fault current is based on two inputs into the protection control circuit. One is the collector to emitter voltage of the device of the IGBT, which is a function of the collector current in the device. A diode is used to clamp this voltage below the positive gate drive power supply voltage, and is called the collector desaturation voltage. The other is the voltage drop between the power and the Kelvin emitter terminal of the device. In an IGBT module, the Kelvin emitter terminal is available externally, because the gate signal is applied between the gate and Kelvin emitter terminals. If we look at the voltage between the power emitter and the Kelvin emitter, we can monitor the voltage drop in the connection inductance between the external power emitter terminal and its internal semiconductor contact, which is caused by the collector current. Here, the Kelvin emitter terminal can be considered as the semiconductor contact point. The inductance is of the order of a few nanohenrys and becomes larger in higher power modules due to longer distances between the semiconductor and the power emitter terminal. This allows an estimate of the IGBT collector current level, which is obtained using a resettable integrator circuit shown in Fig. 1. The parameters of the integrator are based on the connection inductance between the two emitter terminals, the loading of the integrator circuit, and parasitic capacitance of the reset switch. The desaturation voltage detection has a rapid response to low impedance (hard fault) FUL condition. The device current estimator is more effective in detecting soft fault

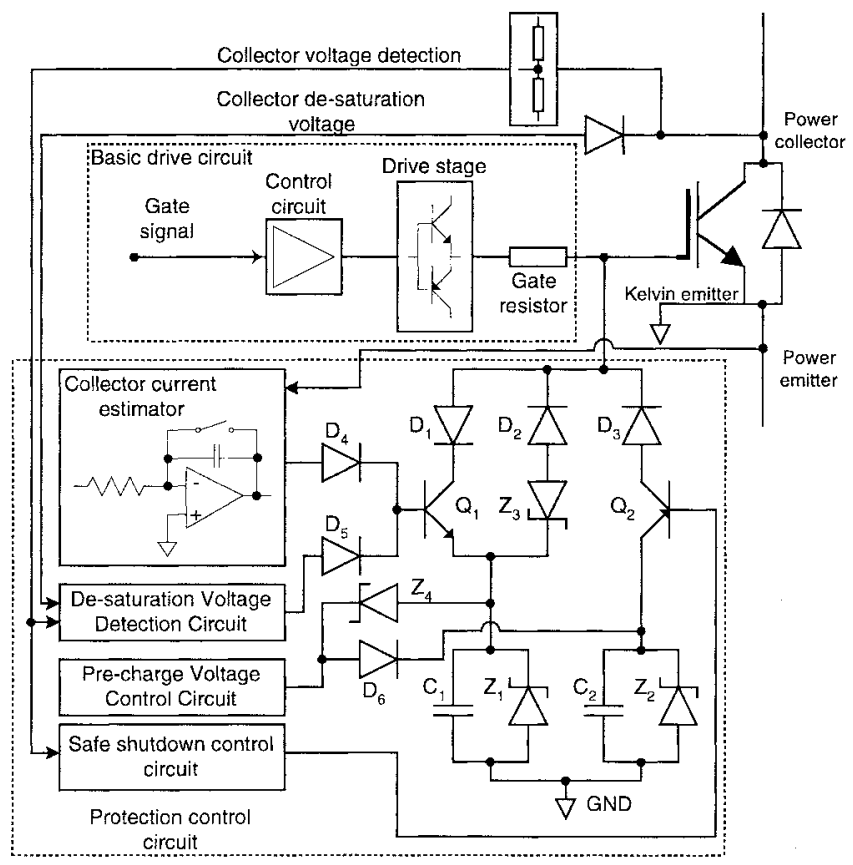

Fig. 1. Schematic diagram of the proposed protection circuit.

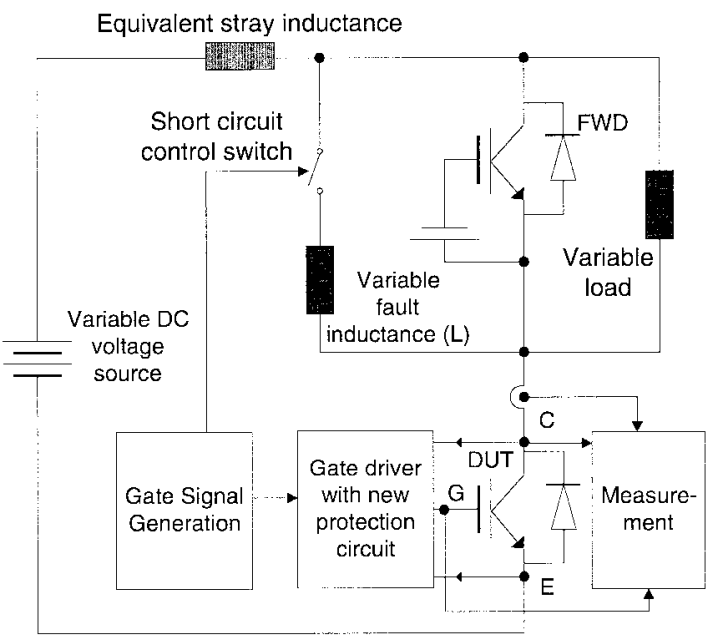

Fig. 2. Test setup.

situations. Direct measurement circuit of the collector voltage, which is added to collector feedback line in Fig. 1, is used to rapidly recognize HSF condition and to distinguish it from normal switching transients of the IGBT [12].

\section{B. Limiting}

Limiting of the current is obtained using the capacitor $C_{1}$ and the zener diode $Z_{1}$ for fast and stable protection. On detection of the fault, the transistor $Q_{1}$ is turned on, which causes $C_{1}$ to charge up to the voltage level of $Z_{1}$, thus discharging the gate. The transistor is activated by the combination of the collector current estimate and the desaturation voltage, which is obtained using diodes $D_{4}$ and $D_{5}$. A large $C_{1}$ results in initial oscillation in the device current and a slow ramp up 


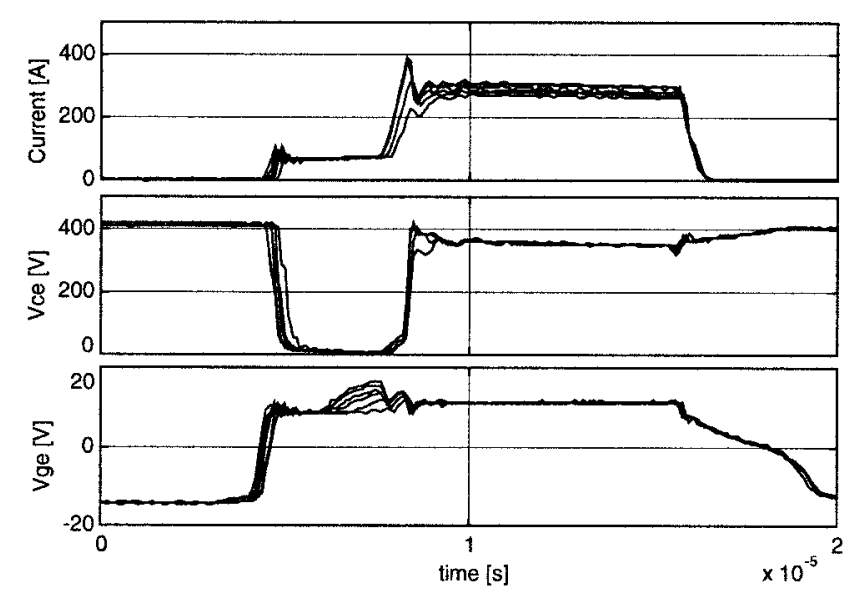

(a)



(b)

Fig. 3. FUL test results for IGBT1 under $V_{g e}$ variation. (a) Without protection. (b) With protection. Selected positive gate voltages are as follows: 14, 15, $16,17,18$, and $19 \mathrm{~V}$. Other conditions are as follows: $C_{1}=30 \mathrm{nF}$, precharge voltage $=4.5 \mathrm{~V}, V_{\mathrm{dc}}=405 \mathrm{~V}, T=24^{\circ} \mathrm{C}, L=200 \mathrm{nH}$.

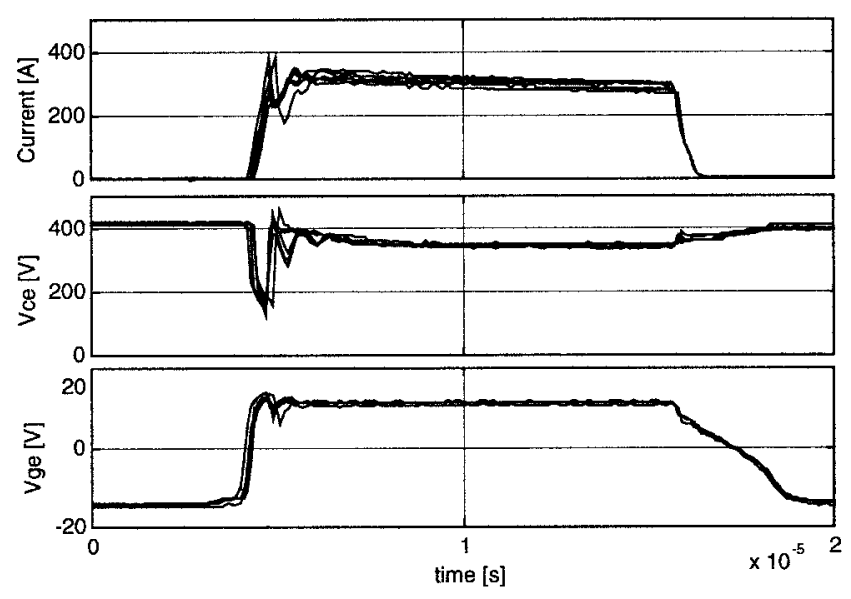

(a)

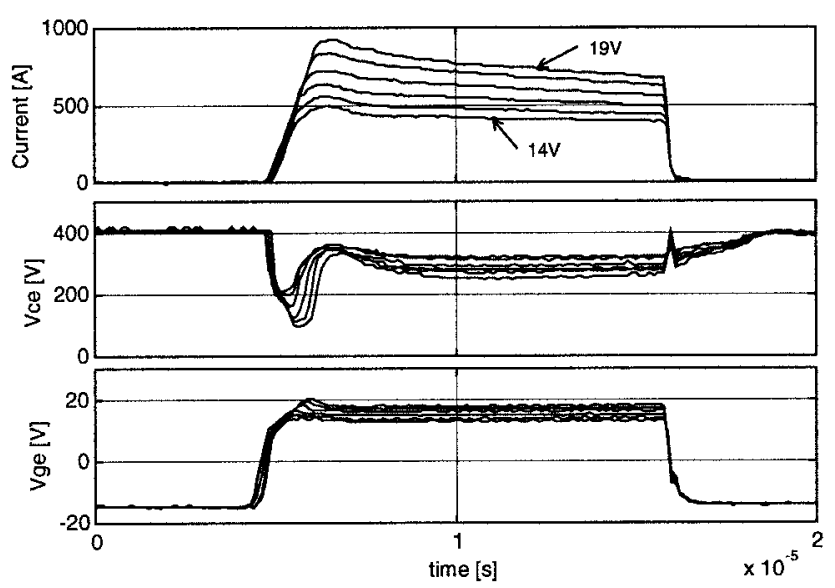

(b)

Fig. 4. HSF test results for IGBT1 under $V_{g e}$ variation. (a) Without protection. (b) With protection. Selected positive gate voltages are as follows: 14 , 15 , $16,17,18$, and $19 \mathrm{~V}$. Other conditions are as follows: $C_{1}=60 \mathrm{nF}$, precharge voltage $=5 \mathrm{~V}, V_{\mathrm{dc}}=405 \mathrm{~V}, T=24^{\circ} \mathrm{C}, L=200 \mathrm{nH}$.

to the clamp current level. A small value of $C_{1}$ results in an increased peak fault current due to insufficient gate discharge. The zener diodes $Z_{3}$ and $Z_{4}$ make the voltage of $C_{1}$ be at the desired voltage level before turning on the IGBT. This precharge voltage compensates for the delay in operation of the protection circuit. A lower precharge voltage will result in the activation of the protection circuit at an earlier instant. The on-state voltage of the IGBT and the voltage drop along the desaturation detection circuit limit the minimum value of the precharge voltage.

\section{Clamping}

The final gate voltage level is clamped by the zener $Z_{1}$. The value of the zener voltage is selected to be above the threshold voltage and depends on the transconductance gain of the driven IGBT. The voltage drops across the transistor $Q_{1}$ and the diode $D_{1}$ have to be considered while selecting the zener diode $Z_{1}$. The clamped gate voltage decides the clamped level of fault current.

\section{Shutdown}

The capacitor $C_{2}$ is placed in parallel with the gate capacitance to turn off the IGBT at a reduced $d V_{g e} / d t$. The collector voltage detection signal provides information to the power converter control circuits about occurrence of the fault and initiates the safe shutdown. The current path changes from $D_{1}$ $Q_{1}-Z_{1}$ during clamping mode to $C_{2}-Q_{2}-D_{3}$ during shutdown. The precharge level of $C_{2}$ is higher than the gate voltage level used for clamping due to the voltage drop corresponding to the conducting paths of the shutdown circuit. This eliminates the small notch in gate voltage caused by the reversal of current from the clamping mode to the safe shutdown mode. The purpose of the diode $D_{6}$ is to obtain decoupling between the precharge voltage levels for $C_{1}$ and $C_{2}$. The zener diode $Z_{2}$ determines the precharge level of $C_{2}$.

\section{E. Fault Monitoring}

Nuisance faults signals can be rejected strongly because the main fault signal sent to the system controller occurs based 


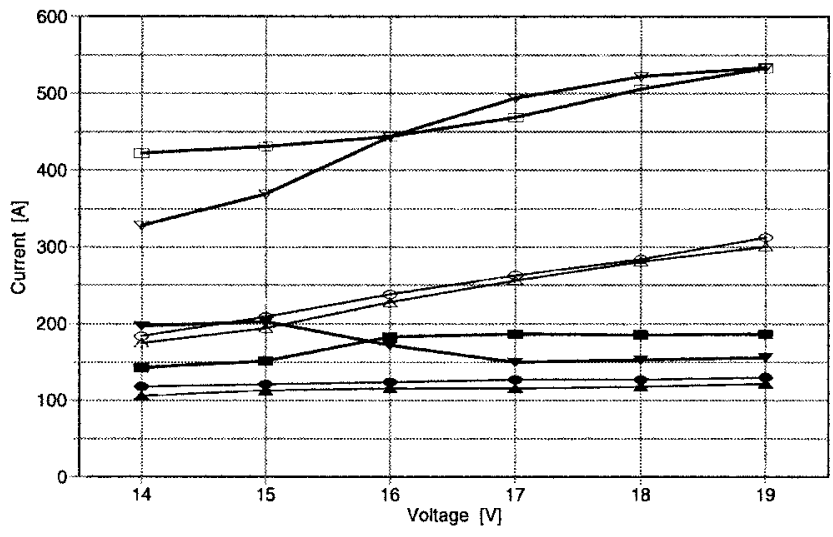

(a)

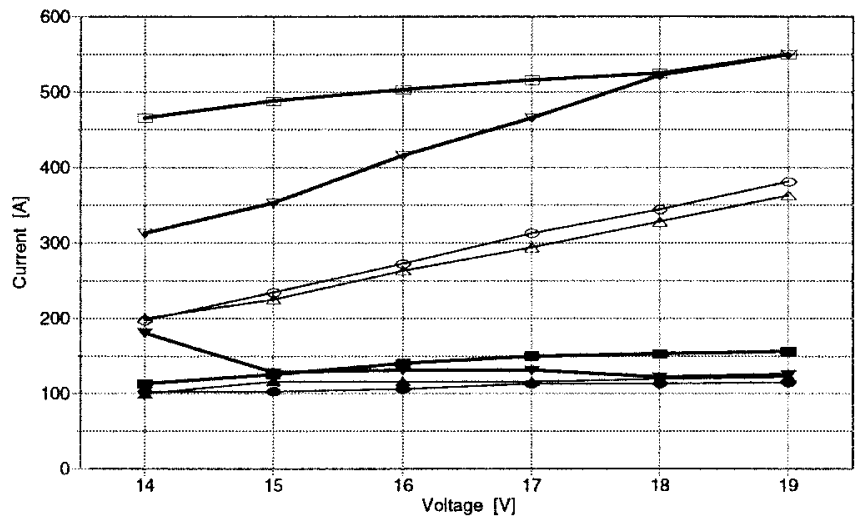

(b)

-Peak fault current under FUL without protection, - peak fault current under HSF without protection, - clamped current level under FUL without protection, - $\triangle$ clamped current level under HSF without protection, --peak fault current under FUL with protection, --peak fault current under HSF with protection, ---clamped current level under FUL with protection, - - clamped current level under HSF with protection.

Fig. 5. Effect of variation of on-state gate voltage on fault parameters. (a) Use of IGBT2 with the operating conditions-FUL: $C_{1}=30 \mathrm{nF}$, precharge $=5$ V; HSF: $C_{1}=20 \mathrm{nF}$, pre-charge $=3.45 \mathrm{~V} ; V_{\mathrm{dc}}=405 \mathrm{~V}, T=24{ }^{\circ} \mathrm{C}, L=200 \mathrm{nH}$. (b) Use of IGBT3 with the operating conditions-FUL: $C_{1}=60$ $\mathrm{nF}$, precharge $=5 \mathrm{~V}$; HSF: $C_{1}=30 \mathrm{nF}$, precharge $=6 \mathrm{~V} ; V_{\mathrm{dc}}=405 \mathrm{~V}, T=24{ }^{\circ} \mathrm{C}, L=200 \mathrm{nH}$.


(a)

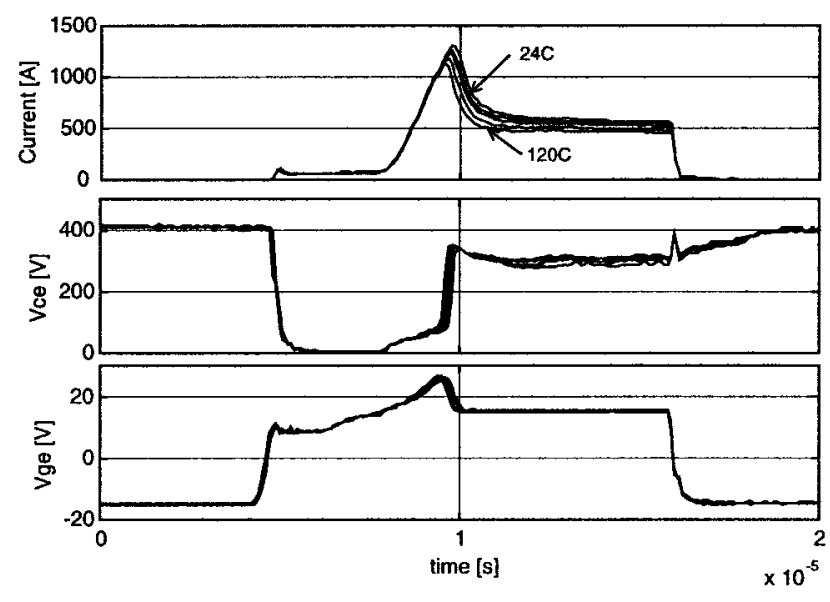

(b)

Fig. 6. FUL test results for IGBT1 under variation of temperature. (a) Without protection. (b) With protection. Selected temperatures are as follows: $24{ }^{\circ} \mathrm{C}$, $40^{\circ} \mathrm{C}, 60^{\circ} \mathrm{C}, 90^{\circ} \mathrm{C}$, and $120^{\circ} \mathrm{C}$. Other conditions are as follows: $C_{1}=60 \mathrm{nF}$, precharge voltage $=5 \mathrm{~V}, V_{\mathrm{dc}}=405 \mathrm{~V}, V_{g e}=15 \mathrm{~V}, L=200 \mathrm{nH}$.

on the measured $V_{c e}$ information. Also, a delay time of a few microseconds is used to report the fault information allowing for momentary transient in the current that could occur without damaging the device. These momentary transients are also held to the clamping current level.

\section{EXPERIMENTAL EVALUATION}

A simple test circuit is set up to verify the validity of the proposed protection circuit, which is shown in Fig. 2. A twopulse method has been used to drive the IGBT with an inductor as the load. The controlled time duration for the first pulse is for obtaining the desired load current, which would be the initial value at turn on of the second pulse. For testing under FUL conditions, the short-circuit control switch in Fig. 2 is turned on while the device under test (DUT) is in on state and conducting load current during the second pulse. On the other hand, for HSF test, the short-circuit control switch is already turned on before the second pulse activates the DUT. The test has been conducted with three different dual IGBT modules: IGBT1: Toshiba MG100Q2YS40 (1200 V, 100 A); IGBT2: Powerex CM75DY-12H (600 V, 75 A); and IGBT3: Fuji 2MBI75-060 (600 V, 75 A). The measured collector current, 


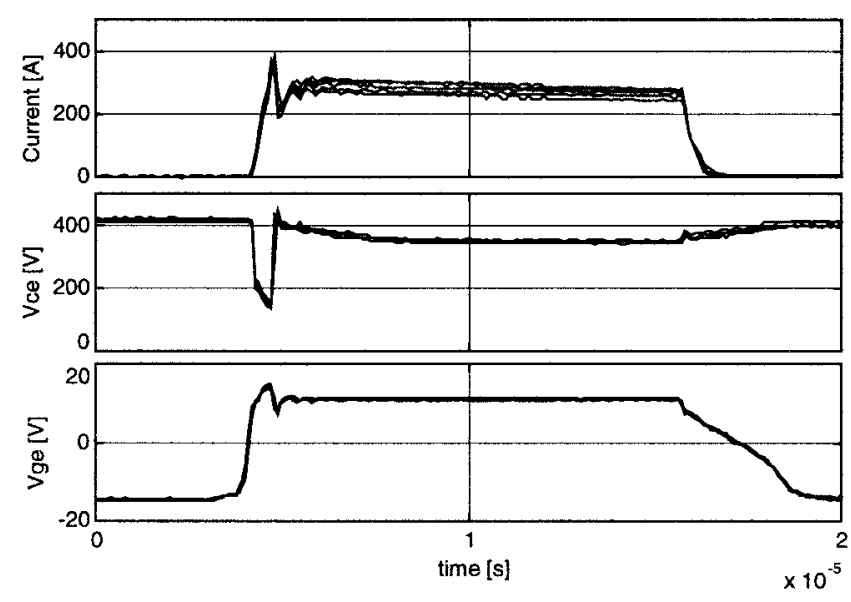

(a)

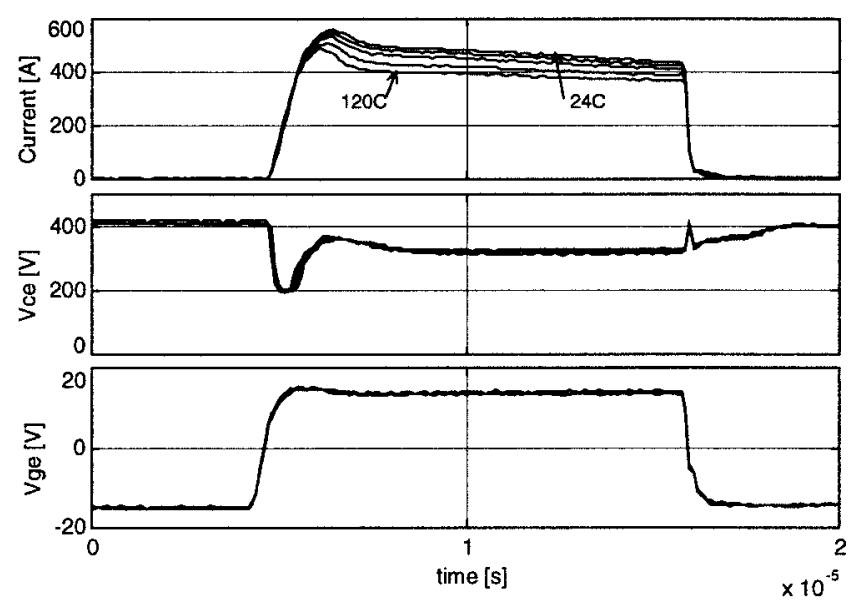

(b)

Fig. 7. HSF test results for IGBT1 under variation of temperature. (a) Without protection. (b) With protection. Selected temperatures are as follows: $24{ }^{\circ} \mathrm{C}$, $40^{\circ} \mathrm{C}, 60^{\circ} \mathrm{C}, 90$, and $120^{\circ} \mathrm{C}$. Other conditions are as follows: $C_{1}=30 \mathrm{nF}$, precharge voltage $=4.5 \mathrm{~V}, V_{\mathrm{dc}}=405 \mathrm{~V}, V_{g e}=15 \mathrm{~V}, L=200 \mathrm{nH}$.

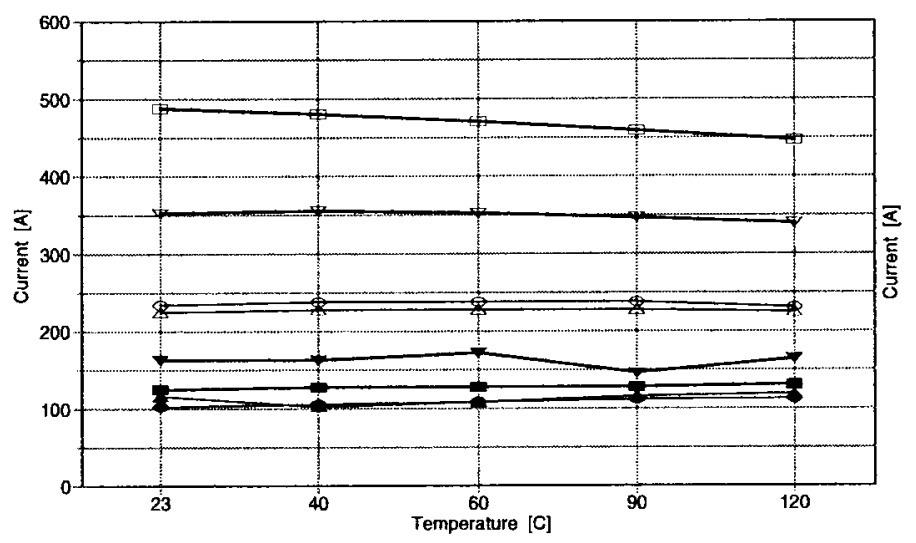

(a)

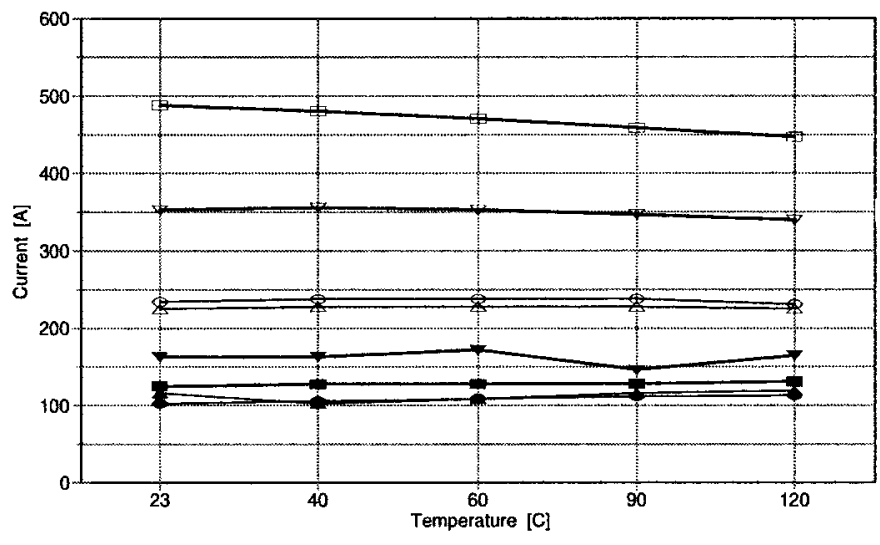

(b)

$\rightarrow$ Peak fault current under FUL without protection, - peak fault current under HSF without protection, - clamped current level under FUL without protection, - $\triangle$-clamped current level under HSF without protection, $\rightarrow$ - peak fault current under FUL with protection, -- peak fault current under HSF with protection, - - clamped current level under FUL with protection, - -clamped current level under HSF with protection.

Fig. 8. Effect of variation of temperature on fault parameters. (a) Use of IGBT2 with the operating conditions-FUL: $C_{1}=30 \mathrm{nF}$, precharge $=5 \mathrm{~V}$; HSF: $C_{1}=20 \mathrm{nF}$, precharge $=3.45 \mathrm{~V} ; V_{\mathrm{dc}}=405 \mathrm{~V}, V_{g e}=15 \mathrm{~V}, L=200 \mathrm{nH}$. (b) Use of IGBT3 with the operating conditions-FUL: $C_{1}=60$ $\mathrm{nF}$, precharge $=5 \mathrm{~V}$; HSF: $C_{1}=30 \mathrm{nF}$, pre-charge $=6 \mathrm{~V} ; V_{\mathrm{dc}}=405 \mathrm{~V}, V_{g e}=15 \mathrm{~V}, L=200 \mathrm{nH}$.

collector voltage, and gate voltage waveforms for IGBT1, and graphs of the peak current and the clamped current levels for IGBT's 2 and 3 for the cases of with and without protection are shown.

\section{A. On-State Gate Voltage Variation}

Fig. 3(a) and (b) shows the test results of FUL while varying the on-state gate voltage, which is the parameter studied during this test. In the case of no protection shown in Fig. 3(a), the peak and the final current levels are strongly dependent on the gate voltages. When the on-state gate voltage is $19 \mathrm{~V}$, the peak current is more than 15 times the rated current. There is not much difference in the $V_{c e}$ waveform. From Fig. 3(b), it can be seen that fault currents are at controlled levels, irrespective of the on-state gate voltage with the active protection circuit. Fig. 4(a) and (b) is for the case of HSF. Fig. 4(b) shows that the protection circuit keeps fault currents within a small envelope for a wide range of the on-state gate voltage levels, as in the case of FUL. On the other hand, from Fig. 4(a), it is shown that the peak and the final current levels increased by a factor of two when the gate voltage was increased from 14 to $19 \mathrm{~V}$. The waveforms in Figs. 3(b) and 4(b) use the selected values of $C_{1}$ and the precharge voltage that result in optimal characteristics of the protection circuit. The tradeoff involved when these parameters are changed is explained in Sections III-D and III-E.The graphs of the key parameters, while using 

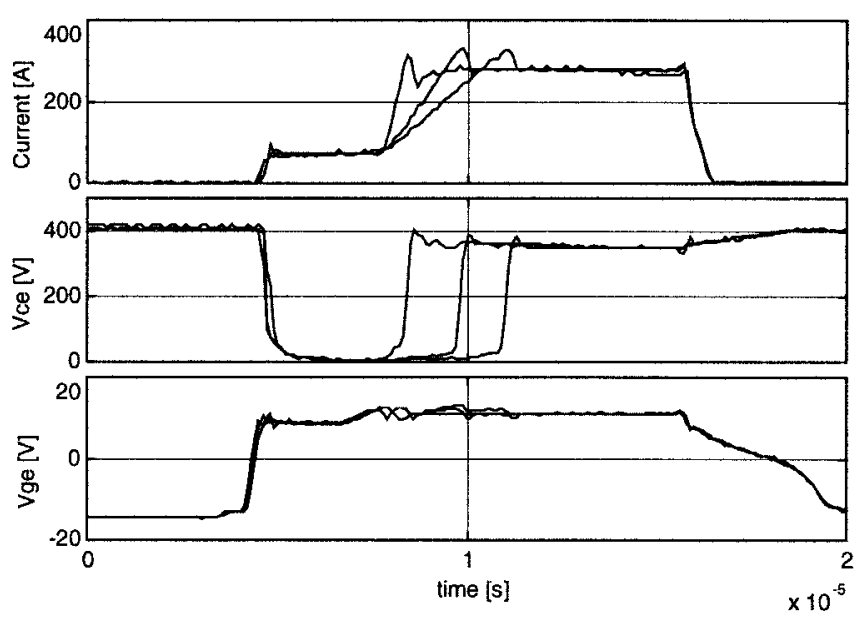

(a)
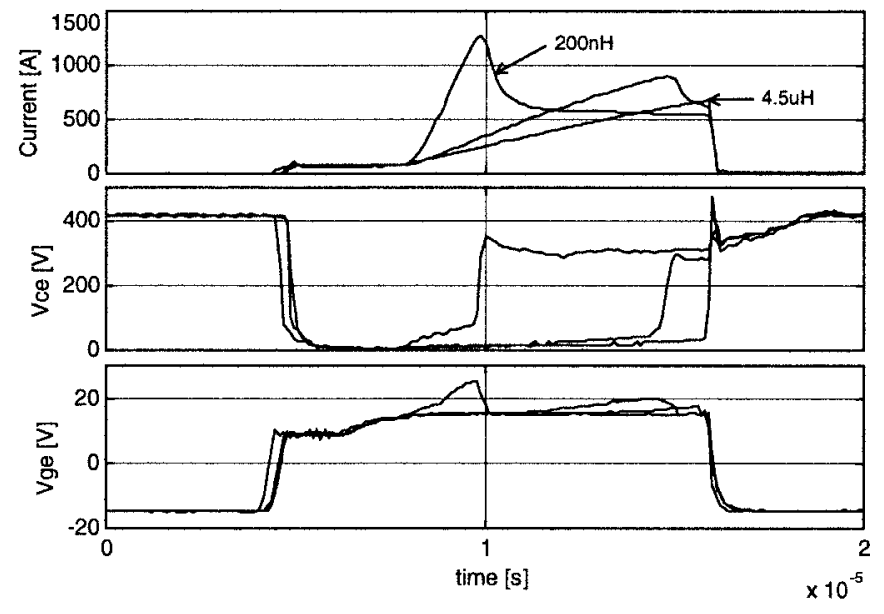

(b)

Fig. 9. FUL test results for IGBT1 under variation of inductance. (a) Without protection. (b) With protection. Selected inductances are as follows: 0.2, 2.5, and $4.5 \mu \mathrm{H}$. Other conditions are as follows: $C_{1}=60 \mathrm{nF}, T=24^{\circ} \mathrm{C}$, precharge voltage $=5 \mathrm{~V}, V_{\mathrm{dc}}=405 \mathrm{~V}, V_{g e}=15 \mathrm{~V}$.

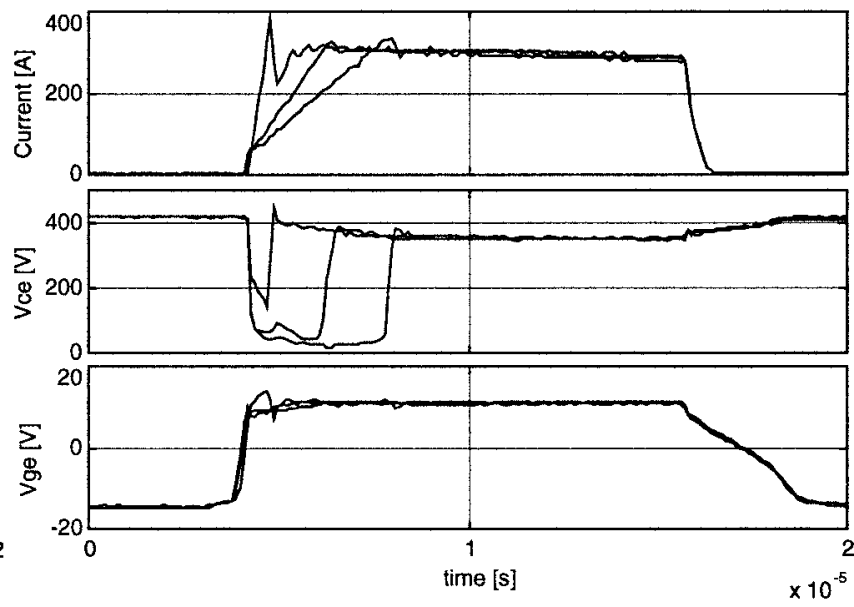

(a)

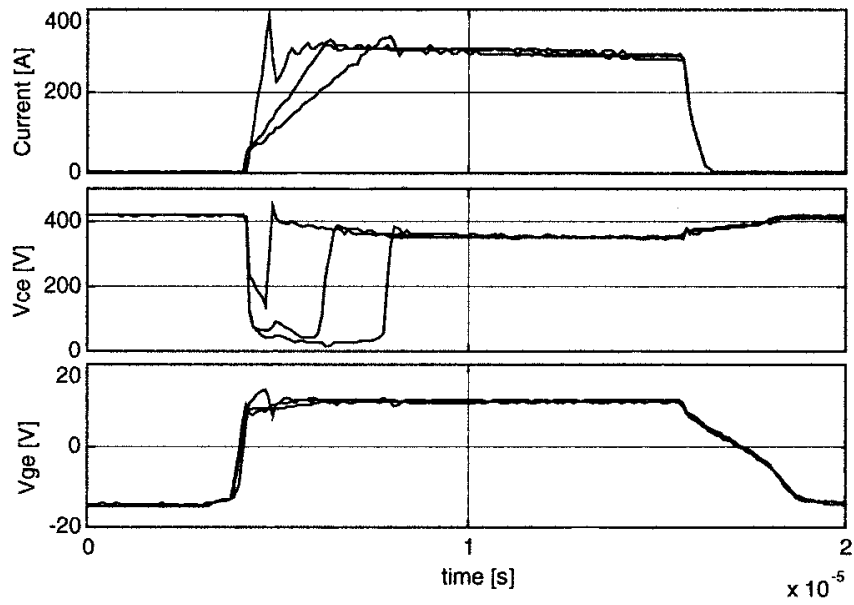

(b)

Fig. 10. HSF test results for IGBT1 under variation of inductance. (a) Without protection. (b) With protection. Selected inductances are as follows: 0.2, 2.5, and $4.5 \mu \mathrm{H}$. Other conditions are given as follows: $C_{1}=30 \mathrm{nF}, T=24{ }^{\circ} \mathrm{C}$, precharge voltage $=4.5 \mathrm{~V}, V_{\mathrm{dc}}=405 \mathrm{~V}, V_{g e}=15 \mathrm{~V}$.

IGBT's 2 and 3, are shown in Fig. 5(a) and (b), respectively. The use of the active protection shows that a significantly lower fault current level can be achieved, irrespective of the gate voltage for all the IGBT's.

\section{B. Temperature Variation}

Figs. 6 and 7 show the effect of operating temperature on IGBT1 for FUL and HSF, respectively. The temperature is measured at the baseplate of the IGBT. During the fault, the chips in the module heat rapidly, but the baseplate stays at approximately a constant temperature. The peak and the final fault current decrease as the temperature is increased, due to the negative temperature coefficient at high current levels. This result indicates that, within the normal operating temperature range, the fault current waveform does not vary significantly if the device is turned off in a short time.
When the active protection circuit is applied, the effect of temperature is reduced. Thus, the impact of fault on the device becomes much smaller. The graphs of the main fault current parameters for IGBT's 2 and 3 are shown in Fig. 8(a) and (b), respectively. The negative temperature coefficient is a desirable characteristic during the fault.

\section{Fault Inductance Variation}

For this test, the variable fault inductance (L), which is shown in Fig. 2, is used to obtain the inductance values of $0.2,2.5$, and $4.5 \mu \mathrm{H}$. Fig. 9(a) shows that the peak fault current is largest for small fault inductance in the case of FUL. As fault inductance decreases, it is necessary for the protection circuit to have a quick reaction to prevent the high peak current. As fault inductance increases, pure desaturationbased fault detection would have a large delay in operation. 


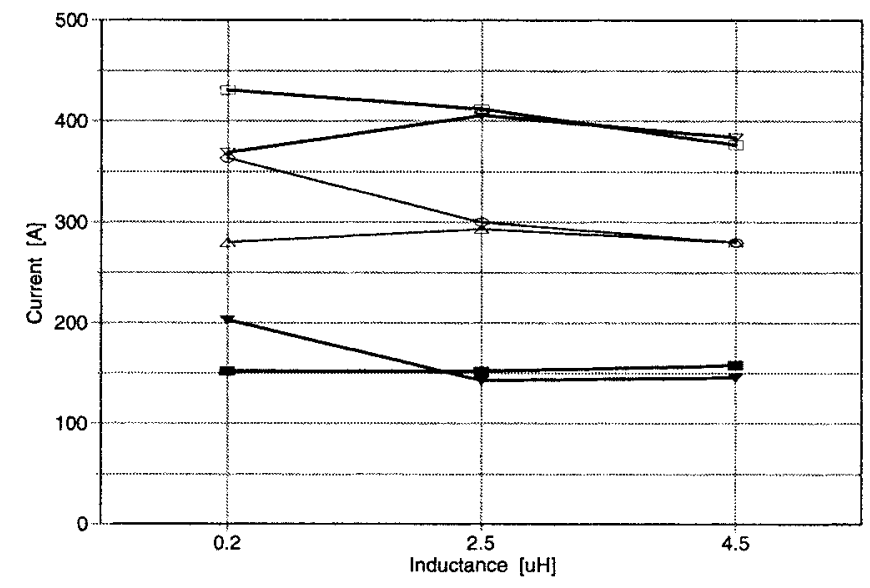

(a)

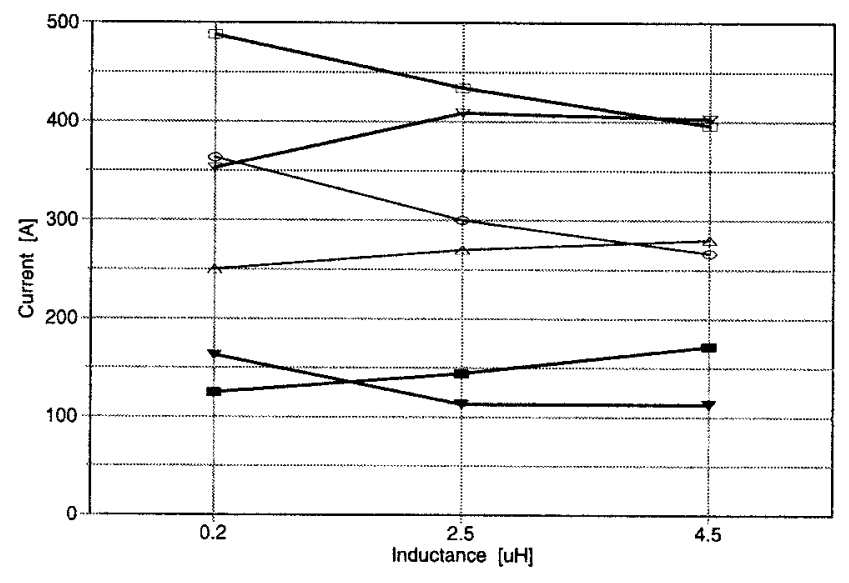

(b)

- Peak fault current under FUL without protection, - - peak fault current under HSF without protection, -cclamped current level under FUL without protection, $\triangle$ clamped current level under HSF without protection,

$\rightarrow$ peak fault current under FUL with protection, $\rightarrow$-peak fault current under HSF with protection.

Fig. 11. Effect of variation of fault inductance on protection circuit performance. (a) Use of IGBT2 with the operating conditions- $\mathrm{FUL}$ : $C_{1}=60 \mathrm{nF}$, precharge $=5 \mathrm{~V}$; HSF: $C_{1}=20 \mathrm{nF}$, precharge $=3.45 \mathrm{~V} ; V_{\mathrm{dc}}=405 \mathrm{~V}, T=24{ }^{\circ} \mathrm{C}, V_{g e}=15 \mathrm{~V}$. (b) Use of IGBT3 with the operating conditions-FUL: $C_{1}=60 \mathrm{nF}$, precharge $=5 \mathrm{~V}$; HSF: $C_{1}=30 \mathrm{nF}$, precharge $=6 \mathrm{~V} ; V_{\mathrm{dc}}=405 \mathrm{~V}, T=24{ }^{\circ} \mathrm{C}, V_{g e}=15 \mathrm{~V}$.

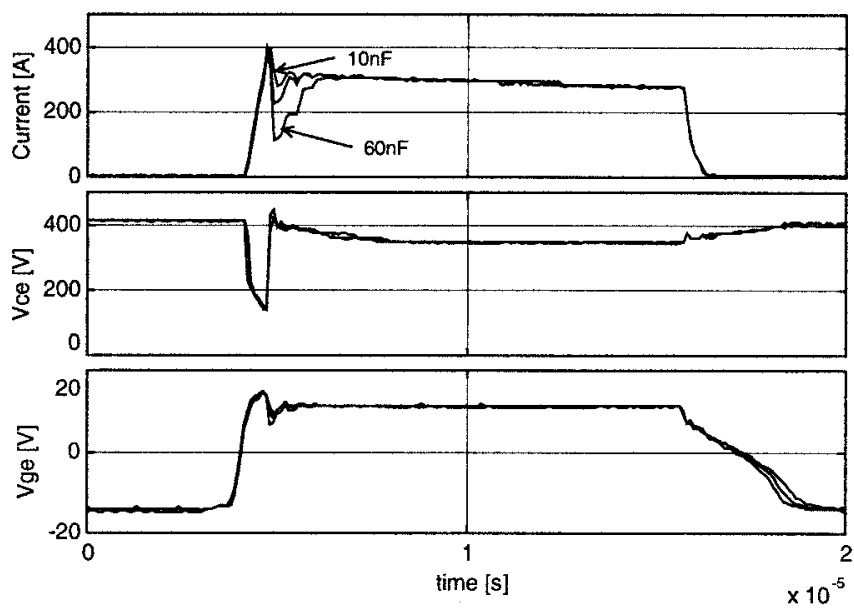

(a)
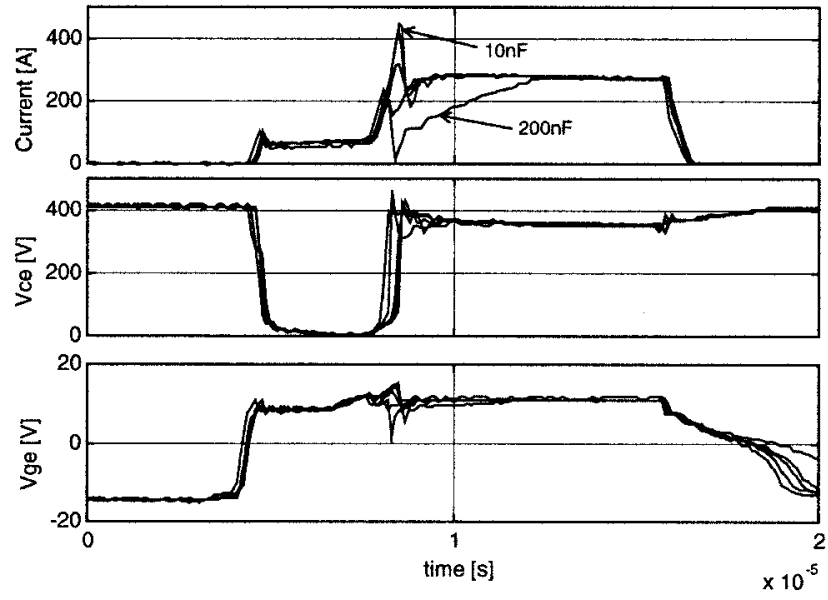

(b)

Fig. 12. Test results for IGBT1 under variation of capacitance $C_{1}$. (a) FUL with selected capacitance as follows: 10, 30, 60, 100, and 200 nF. Precharge is at $4.8 \mathrm{~V}$. (b) HSF with selected capacitance as follows: 10, 30, and $60 \mathrm{nF}$. Precharge is at $5.0 \mathrm{~V}$. Other conditions are given as follows: fault inductance $=200 \mathrm{nH}, T=24{ }^{\circ} \mathrm{C}, V_{\mathrm{dc}}=405 \mathrm{~V}, V_{g e}=15 \mathrm{~V}$.

Therefore, it would not be possible to limit the peak fault current and to estimate the exact fault current level without using a current sensor. On the other hand, in the case of HSF shown in Fig. 10(a), the peak fault current increases as the fault inductance is increased. Therefore, it is difficult to exactly recognize fault conditions at a similar current level for both cases. The proposed active protection circuit can detect and limit the fault current at the same level not only for a wide range of fault inductance, but also for both FUL and HSF, as shown in Figs. 9(b) and 10(b). The graphs of the fault current parameters for IGBT's 2 and 3 are shown in Fig. 11(a) and (b), respectively. The trend in all the cases without protection is similar, indicating a reduction in the difference between the collector current levels for FUL and HSF as the fault inductance is increased.

\section{Circuit Parameter Cl Variation}

Fig. 12(a) and (b) shows the effect of variation of the capacitor $C_{1}$, which is designated in Fig. 1, on the response of the protection circuit for FUL and HSF. A large $C_{1}$ results in the device current reaching almost zero and then slowly building up to the clamped current level. A small $C_{1}$ is not effective in discharging the gate capacitance rapidly and results in a higher initial peak in fault current. Fig. 13(a) and (b) 


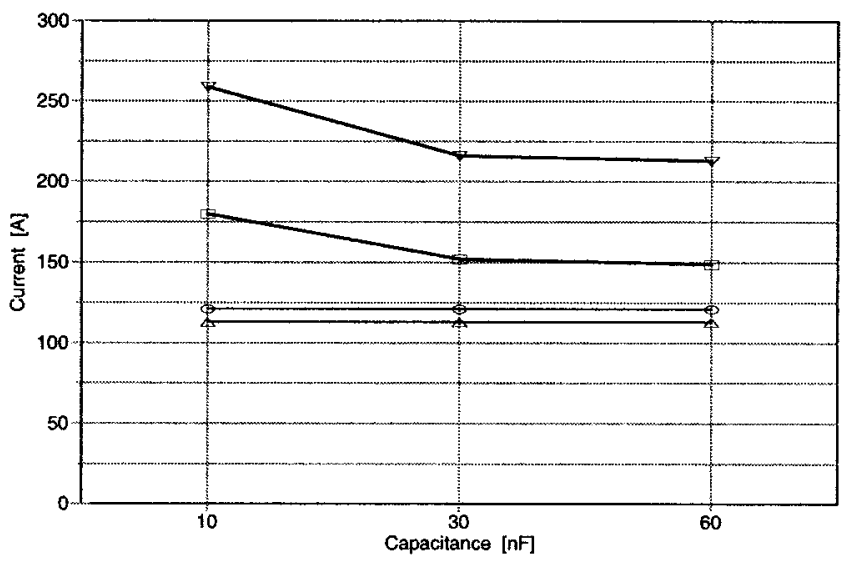

(a)



(b)

$\rightarrow$ peak fault current under FUL with protection, - peak fault current under HSF with protection, - - clamped current level under FUL with protection, $\triangle-$ clamped current level under HSF with protection.

Fig. 13. Effect of variation of protection capacitor $C_{1}$ on fault parameters. (a) Use of IGBT2 with the operating conditions-FUL: precharge $=4.55$ V; HSF: precharge $=3.45 \mathrm{~V} ; L=200 \mathrm{nH}, T=24{ }^{\circ} \mathrm{C}, V_{g e}=15 \mathrm{~V}, V_{\mathrm{dc}}=405 \mathrm{~V}$. (b) Use of IGBT3 with the operating conditions-FUL: precharge $=5.9 \mathrm{~V} ;$ HSF: precharge $=6 \mathrm{~V} ; L=200 \mathrm{nH}, T=24{ }^{\circ} \mathrm{C}, V_{g e}=15 \mathrm{~V}, V_{\mathrm{dc}}=405 \mathrm{~V}$.
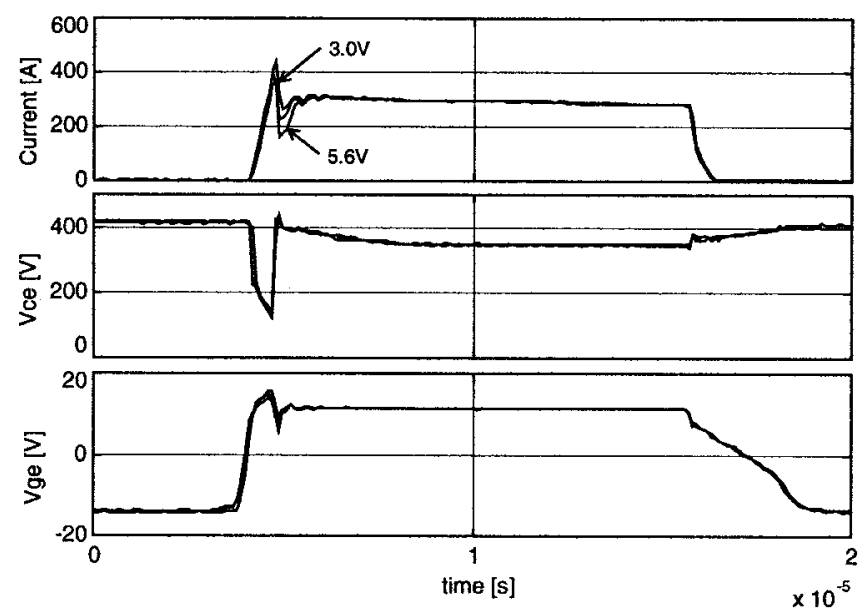

(a)
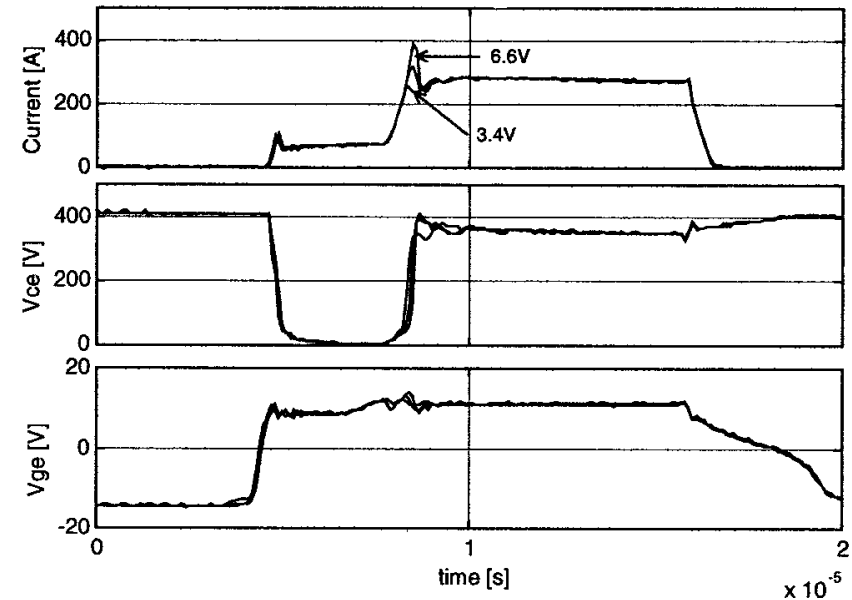

(b)

Fig. 14. Test results for IGBT1 under variation of precharge voltage of $C_{1}$. (a) FUL with selected precharge voltage values as follows: 3.4 , 4.8, and 6.6 V. $C_{1}$ is $60 \mathrm{nF}$. (b) HSF with selected precharge voltage values as follows: $3.0,4.0$, and $5.6 \mathrm{~V}$. $C_{1}$ is $30 \mathrm{nF}$. Other conditions are given as follows: fault inductance $=200 \mathrm{nH}, T=24{ }^{\circ} \mathrm{C}, V_{\mathrm{dc}}=405 \mathrm{~V}, V_{g e}=15 \mathrm{~V}$.

shows the influence of $C_{1}$ on the performance of the protection circuit for IGBT's 2 and 3. It can be seen from the graph that the variation of capacitance has a greater effect on limiting the peak current levels in the case of FUL than HSF. This is because of the larger delay in activation of the protection circuit in case of HSF. Also, the variation of $C_{1}$ does not affect the clamped current level, which is determined by the zener $Z_{1}$.

\section{E. Precharge Voltage Variation}

Fig. 14(a) and (b) shows the effect of the precharge voltage level on the response of the protection circuit for FUL and HSF, respectively. It can be seen that lowering the precharge voltage is effective in lowering the initial peak in fault current.
The precharge voltage variation has a greater effect on FUL than HSF. This is because of the need to have a minimum delay before activation of the desaturation detection circuit. Advancing the activation of the protection circuit by using the measured $V_{c e}$ voltage can minimize this effect. Similar results obtained for IGBT's 2 and 3 are shown in the graphs of Fig. 15(a) and (b), respectively.

\section{F. Design of the Protection Circuit}

The capacitor $C_{1}$ selected for the tests has been proportional to the input capacitance of the IGBT. As devices of comparable ratings have similar values of input capacitance, the selection of $C_{1}$ can be narrowed to a smaller range. A design approach is to select initial $C_{1}$ to be equal to the input capacitance of 


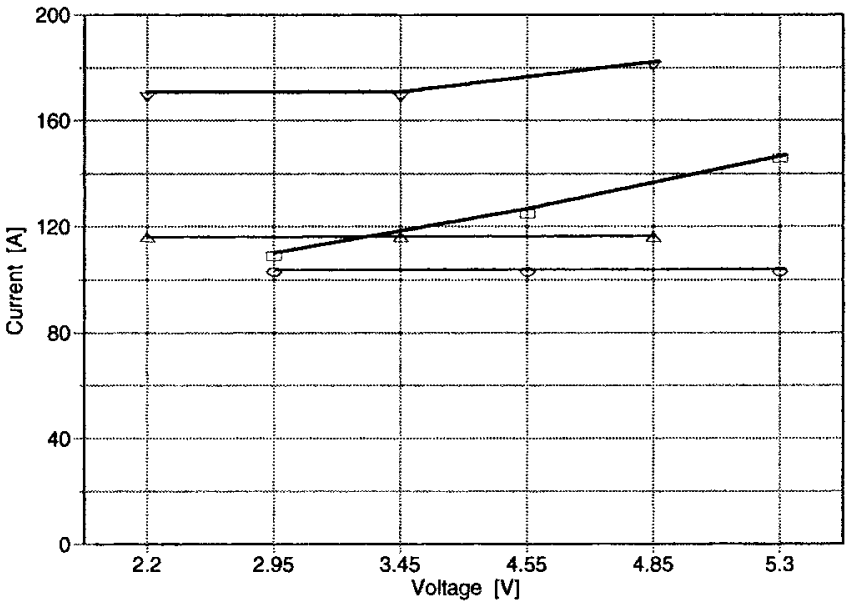

(a)

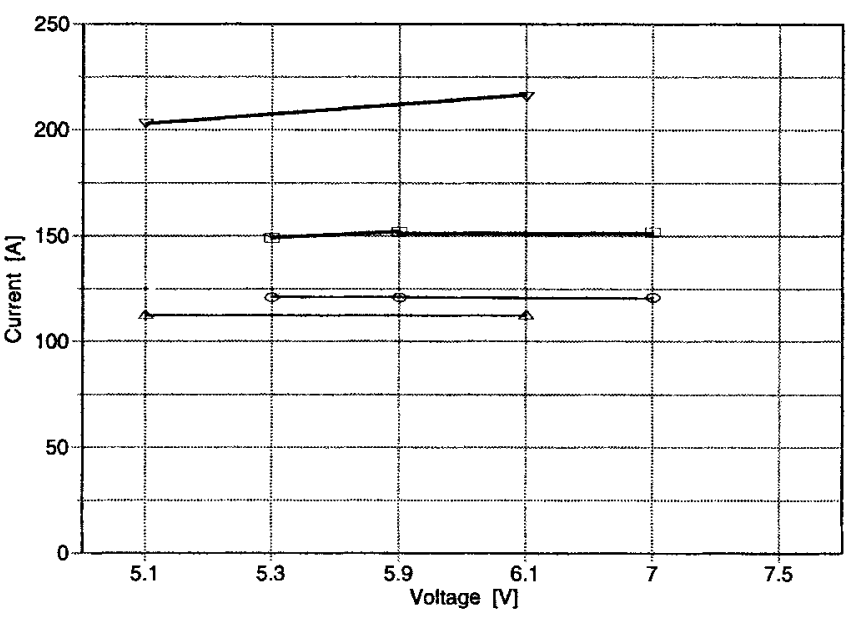

(b)

$\rightarrow$ Peak fault current under FUL with protection, $\rightarrow$ peak fault current under HSF with protection, $\rightarrow$ - clamped current level under FUL with protection, - $\ldots$ - clamped current level under HSF with protection.

Fig. 15. Effect of variation of precharge voltage of $C_{1}$ on fault parameters. (a) Use of IGBT2 with the operating conditions-FUL: $C_{1}=30 \mathrm{nF}$; HSF: $C_{1}=20 \mathrm{nF}, L=200 \mathrm{nH}, T=24{ }^{\circ} \mathrm{C}, V_{g e}=15 \mathrm{~V}, V_{\mathrm{dc}}=405 \mathrm{~V}$. (b) Use of IGBT3 with the operating conditions-FUL: $C_{1}=60 \mathrm{nF}$; HSF: $C_{1}=30 \mathrm{nF} ; L=200 \mathrm{nH}, T=24{ }^{\circ} \mathrm{C}, V_{g e}=15 \mathrm{~V}, V_{\mathrm{dc}}=405 \mathrm{~V}$

TABLE I

Peak Power and Energy Dissipation in the IGBT's With and Without Protection [Energy Dissipation is Normalized to 1.0 For OPERATION Without Protection; Other Conditions ARe: $V_{\text {ge_on }}=15 \mathrm{~V}, V_{\mathrm{dc}}=405$ $\mathrm{V}, T=24{ }^{\circ} \mathrm{C}, L=200 \mathrm{nH}$ ( $L$ is the Fault Inductance Shown IN Fig. 2)]

\begin{tabular}{l|c|c|c|c}
\hline \hline \multirow{2}{*}{ Device } & \multicolumn{2}{|c|}{ FUL } & \multicolumn{2}{c}{ HSF } \\
\cline { 2 - 5 } & w/o [kW] & w [kW] & w/o [kW] & w [kW] \\
\hline IGBT1 & 423 & 110 & 201 & 125 \\
MG100Q2YS40 & $(1.0)$ & $(0.59)$ & $(1.0)$ & $(0.73)$ \\
\hline IGBT2 & 178 & 44.3 & 135 & 62.0 \\
CM75DY-12H & $(1.0)$ & $(0.46)$ & $(1.0)$ & $(0.48)$ \\
\hline IGBT3 & 156 & 55.9 & 145 & 82.5 \\
2MBI75-060 & $(1.0)$ & $(0.45)$ & $(1.0)$ & $(0.58)$ \\
\hline
\end{tabular}

the IGBT. The range of precharge voltage for $C_{1}$ is from the nominal on-state collector voltage of the IGBT to the zener voltage of $Z_{1}$. The initial precharge voltage is selected to be close to the threshold voltage of the device. Optimal performance is obtained from the experimental tests. There exists a tradeoff in the choice of $C_{1}$ and precharge voltage between HSF and FUL. The initial peak in the case of HSF is more sensitive to delay in the circuit operation and the value of $C_{1}$. This delay has to be minimized by using both collector desaturation voltage and collector voltage detection. Selecting the precharge voltage can effectively control the peak fault current for FUL. The final choice in the results above is by experimental evaluation. The value of $C_{2}$ is selected so that the time constant given by the gate resistance and the effective gate capacitance is increased by at least a factor of four. The value of $Z_{1}$ is based on the gate voltage versus collector current characteristics of the IGBT, which can be obtained from the data sheets. In the tests above, $Z_{1}$ was selected so that the clamped fault current is approximately four times the rated current of the device.

\section{G. Peak Power and Energy Dissipation}

Table I lists a comparison of the peak power and the energy dissipation between the cases of with and without the active protection circuit, for FUL and HSF for three different IGBT's. Under the given operating conditions, the peak power dissipation is reduced by a factor of 3 for FUL and by a factor of 1.8 for HSF on an average value by using the active protection circuit. The energy dissipation is reduced by a factor of 0.5 on an average. The reduction of power dissipation improves the ability of the device to endure the fault. This allows for better low-pass filtering of the fault signals and can lead to improved noise immunity.

\section{CONCLUSION}

This paper has shown a new active protection circuit for IGBT's. The experimental results obtained under various conditions indicate that the proposed circuit has the following features.

- Precise detection of the overcurrent can be done without an additional current sensor.

- Fast detection and quick reaction of the protection circuit are enough to effectively limit the initial peak current.

- Precise clamping of fault current reduces the peak power and the energy dissipation and, hence, increases the endurance time of fault current.

- Clamping of fault current and measurement of $V_{c e}$ can improve the error signal noise immunity. 
- Safe shutdown of fault currents can control the overvoltage level at turn-off.

The circuit is able to control not only the steady-state, but also the transient fault currents. In particular, the circuit has the ability to activate the protection circuit and limit fault current at a similar current level, irrespective of the fault impedance and the on-state gate voltage.

\section{REFERENCES}

[1] M. Trivedi and K. Shenai, "Internal dynamics of IGBT during short circuit switching," in Proc. IEEE BCTM'96, 1996, pp. 77-80.

[2] G. Majumdar and D. Medaule, "A new generation of intelligent power devices for motor drive applications," in Proc. Inst. Elect. Eng. Power Electronics and Variable Speed Drives'94, Oct. 1994, pp. 35-41,.

[3] S. Konrad, "A new driver for voltage-controlled components with integrated short-circuit protection," EPE J., vol. 4, no. 3, pp. 9-13, 1994.

[4] S. Ochi, "Driving and protecting large die IGBT and MOS power devices," EPE J., vol. 4, no. 3, pp. 14-20, 1994

[5] R. Chokawala and G. Castino, "IGBT fault current limiting circuit," in Conf. Rec. IEEE-IAS Annu. Meeting, 1993, pp. 1339-1345.

[6] R. Chokawala and S. Sobhani, "Switching voltage transient protection schemes for high current IGBT modules," in Proc. IEEE-APEC'94, 1994, pp. 459-468.

[7] H. G. Eckel and L. Sack, "Experimental investigation on the behavior of IGBT at short current during the on state," in Proc. IEEE-IECON'94, 1994, pp. 118-123.

[8] H. G. Eckel and L. Sack, "Optimization of short circuit behavior of NPT IGBT by gate drive," in Proc. EPE Conf., 1995, vol. 2, pp. 213-218.

[9] F. Blaabjerg and J. K. Pedersen, "An optimum drive and clamp circuit design with controlled switching for a snubberless PWM-VSI-IGBT inverterleg," in Proc. IEEE-PESC'92, 1992, pp. 289-297.

[10] Y. Tadros, G. Junge, and S. Salama, "Design aspects of high power PWM inverters with IGBT," in Proc. EPE Conf., 1991, vol. 2, pp. $83-88$.

[11] H. G. Eckel and L. Sack, "Optimization of the turn-off performance of IGBT at overcurrent and short-circuit current," in Proc. EPE Conf., 1993, vol. 2, pp. 317-322.

[12] S. Gedia, R. Marquardt, and R. Sommer, "High power IGBT converters with new gate drive and protection circuit," in Proc. EPE Conf., 1995, vol. 1, pp. 66-70.

[13] F. Bauer, H. Dettmer, W. Fichtner, H. Lendenmann, T. Stockmeier, and U. Thiemann, "Design considerations and characteristics of Rugged Punchthrough (PT) IGBT's with $4.5 \mathrm{kV}$ blocking capacity," in Proc. Int. Symp.Power Semiconductor Devices and IC's, 1996, pp. 327-330.

[14] R. Chokhawala, J. Catt, and B. Pelly, "Gate drive considerations for IGBT modules," in Conf. Rec. IEEE-IAS Annu. Meeting, 1992, pp. $1186-1195$.

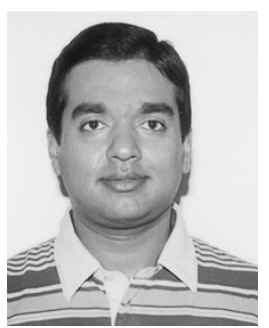

Vinod John (S'92) received the B.Tech. degree in electrical engineering from the Indian Institute of Technology, Madras, India, in 1992 and the M.S.E.E. degree from the University of Minnesota, Minneapolis, in 1994. He is currently working towards the Ph.D. degree at the University of Wisconsin, Madison.

His primary areas of interest are IGBT gate drive technology, high-power hard- and soft-switched converters and their control, and motor drives.

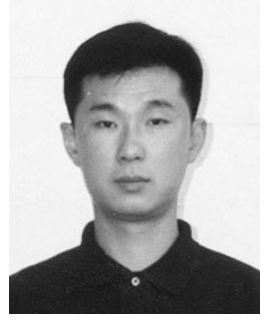

Bum-Seok Suh was born in Seoul, Korea, in 1966. $\mathrm{He}$ received the B.E., M.E., and Ph.D. degrees in electrical engineering from Hanyang University, Seoul, Korea, in 1989, 1991, and 1996, respectively.

During 1996, he was with Hanyang University as a Research Associate, involved in the development of high-power IGBT inverters. From 1996 to 1998, he was with the Department of Electrical and Computer Engineering, University of Wisconsin, Madison, as a Research Associate, involved in the development of an active gate drive and protection circuit for high-power IGBT's. Since 1998, he has been with the Power Device Division, Samsung Electronics, Puchon City, Korea, as a Staff Engineer. His research interests include application of power semiconductor devices, high-power static converters, and power electronics.

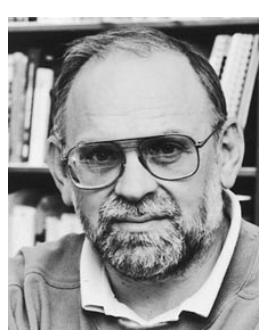

Thomas A. Lipo (M'64-SM'71-F'87) was born in Milwaukee, WI. He received the B.E.E. and M.S.E.E. degrees from Marquette University, Milwaukee, WI, in 1962 and 1964, respectively, and the $\mathrm{Ph} . \mathrm{D}$. degree in electrical engineering from the University of Wisconsin, Madison, in 1968.

From 1969 to 1979, he was an Electrical Engineer in the Power Electronics Laboratory of Corporate Research and Development, General Electric Company, Schenectady, NY. He became a Professor of Electrical Engineering at Purdue University, West Lafayette, IN, in 1979 and, in 1981, he joined the University of Wisconsin, Madison, in the same capacity. He is presently the W. W. Grainger Professor for Power Electronics and Electrical Machines Co-Director of the Wisconsin Electric Machines and Power Electronics Consortium and Director of the Wisconsin Power Electronics Research Center.

Dr. Lipo has received three major awards from three different IEEE Societies. In 1986, he received the Outstanding Achievement Award from the IEEE Industry Applications Society for his contributions to the field of ac drives and, in 1990, he received the William E. Newell Award of the IEEE Power Electronics Society for contributions to the field of power electronics. He received the 1995 Nicola Tesla IEEE Field Award "for pioneering contributions to simulation of and application to electric machinery in solid-state ac motor drives." He has served in various capacities for three IEEE Societies, including President of the IEEE Industry Applications Society in 1994. 